\title{
Rapid characterisation of Candida albicans by pyrolysis mass spectrometry
}

\author{
G. C. WHITE, P. R. SISSON*, R. FREEMAN $\dagger$ and B. D. COOKSON \\ Laboratory of Hospital Infection, Division of Hospital and Respiratory Infection. Central Public Health Laboratory, \\ Colindale Avenue, London, ${ }^{*}$ Regional Public Health Laboratory, Westgate Road, Newcastle upon Tyne and \\ $\dagger$ Department of Microbiology, Medical School, Framlington Place, Newcastle upon Tyne
}

\begin{abstract}
Summary. Clinical isolates (41) of Candida spp. from three possible outbreaks of nosocomially-acquired infection were compared by pyrolysis mass spectrometry (PMS) and by a combined morphotyping and resistotyping (M-R typing) method. Both systems characterised all the isolates and distinguished one isolate of $C$. tropicalis and another of $C$. glabrata from the 39 isolates of $C$. albicans. Results from both systems suggested that crossinfection with a single strain contributed to two of the outbreaks. In several instances, more than one strain of $C$. albicans was found amongst multiple isolates from the same patient. PMS is a simple, rapid and objective technique capable of characterising C. albicans isolates; discrimination was similar to M-R typing.
\end{abstract}

\section{Introduction}

The epidemiology of Candida albicans infections is poorly understood because of the lack of a reliable typing system. Early attempts at typing Candida spp. relied upon phenotypic variations that lacked sensitivity and reproductibility, were open to observer bias and often could not be confirmed by other methods. Combinations of methods such as morphotyping, resistance patterns and serological agglutination reactions, used by reference centres, have never been entirely satisfactory. ${ }^{1.2}$ Of these combined methods, morphotyping plus resistotyping (M-R typing) is the most suitable presently available.

New approaches based on DNA analysis have been introduced, ${ }^{3.4}$ but these require specialised equipment, expensive reagents and considerable technical expertise. Furthermore, they are slow, labour intensive, and gel-to-gel variation limits the number of isolates that can be conveniently examined. These approaches have thus been termed "fingerprinting" methods rather than typing methods.

Pyrolysis mass spectrometry (PMS) has been used successfully in rapid inter-strain comparisons for many bacterial species, ". and has been used to authenticate two reference strains of $C$. albicans. ${ }^{6}$ In this report the results of M-R typing and PMS characterisation of $C$. albicans isolates from three possible hospital outbreaks are compared.

\section{Materials and methods}

\section{Source of isolates}

Clinical isolates of Candida spp. from three geographically distinct hospitals were selected for the study. These comprised: nine isolates from seven patients on an intensive care unit (hospital A; table I); 25 isolates from four patients on one ward of hospital $\mathrm{B}$, over a 4-month period (table II); and seven isolates from a neonatal intensive care unit (hospital $C$; table III).

\section{Morphotyping and resistotyping}

Morphotyping was performed by a modification of the method of Phongpaichit et $a l^{;}$Coding was simplified to include only six fringe states and two colonial surface types. ${ }^{*}$ Recognised fringe types were: no fringe $(\mathrm{O})$; discontinuous $(\mathrm{D})$; narrow fine $(\mathrm{N}-\mathrm{F})$; narrow coarse $(\mathrm{N}-\mathrm{C})$; wide fine $(\mathrm{W}-\mathrm{F})$ and wide coarse (W-C). The surface state characters were not used as they showed poor reproducibility. ${ }^{*}$

Resistotyping and code nomenclature were as described previously. ${ }^{*}$ Chemical concentrations and codes were: sodium selenite $(13 \mathrm{~g} / \mathrm{L}$. A); boric acid $(25 \mathrm{~g} / \mathrm{L}, \mathrm{B})$; cetrimide $(3 \mathrm{~g} / \mathrm{L}, \mathrm{C})$; malachite green $(0.01 \mathrm{~g} / \mathrm{L}, \mathrm{D}) ; \mathrm{CuSO}_{4}(25 \mathrm{~g} / \mathrm{L}, \mathrm{E})$; benzalkonium chloride $(1 \mathrm{~g} / \mathrm{L}, \mathrm{F})$; chlorhexidine $(2 \mathrm{~g} / \mathrm{L} . \mathrm{G})$; mercurochrome $(2.5 \mathrm{~g} / \mathrm{L}, \mathrm{H})$ ) sodium arsenate $(50 \mathrm{~g} /$ L, I); 5-fluorocytosine $(0.75 \mathrm{~g} / \mathrm{L}, \mathrm{J})$ and $\mathrm{NaCl}$ $(93.75 \mathrm{~g} / \mathrm{L}, \mathrm{K})$. Resistotype control (RC) strains were RC6, RC7, RC8, RC9 and RC10.." When resistotyping gave unusual results, isolates were identified by the API 20C AUX system (API-bioMérieux UK Lid). 


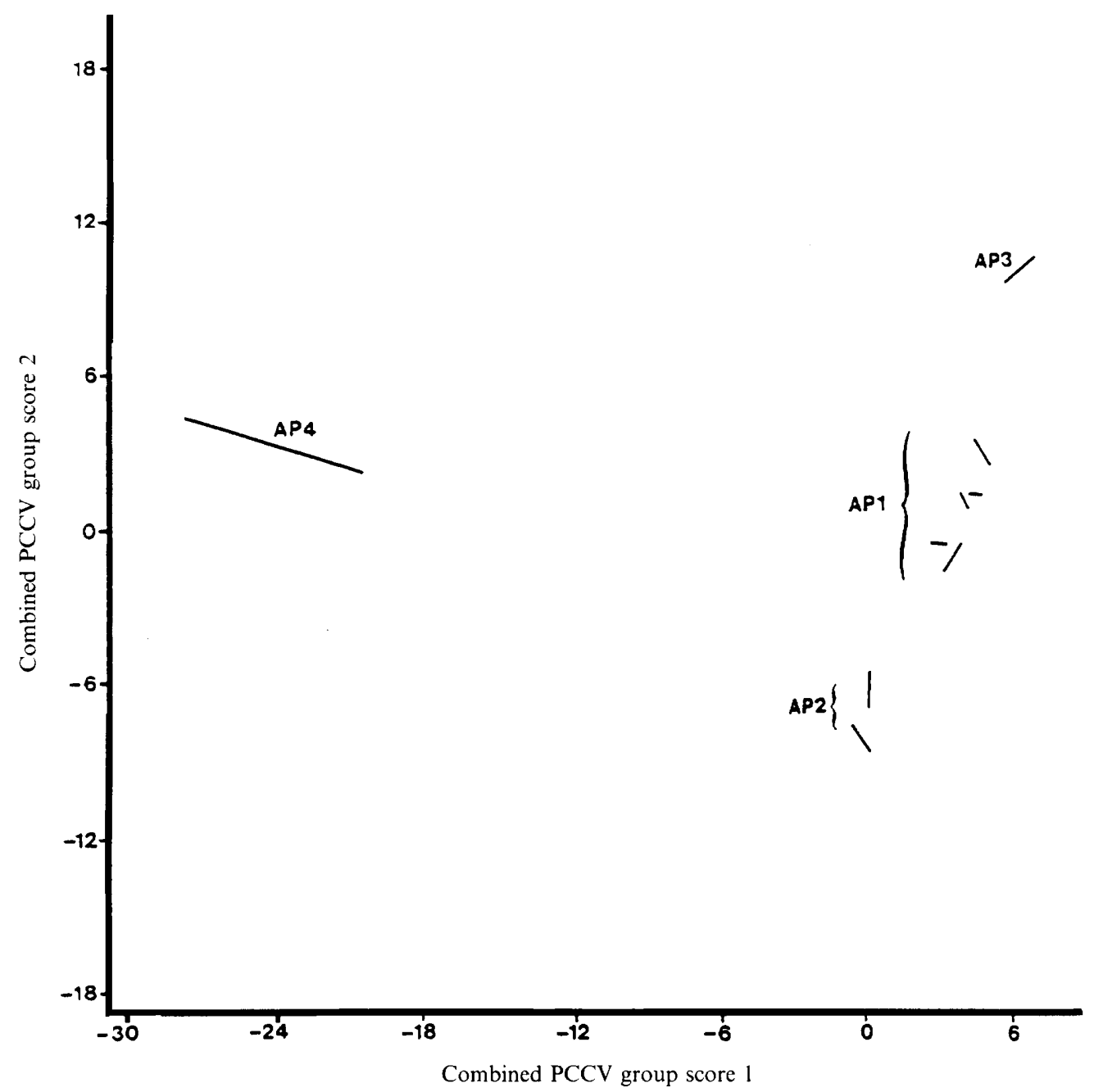

Fig. 1. Ordination diagram of spectral data for duplicate subcultures of nine isolates of yeast from outbreak A. In this and subsequent figures. the axes represent the first two canonical discriminant functions (complex statistically derived axes reflecting the major spectrum differences) and the means of triplicate analysis of subcultures of the same isolate have been joined.

Table I. Details of nine isolates from hospital A

\begin{tabular}{|c|c|c|c|c|c|c|c|}
\hline $\begin{array}{c}\text { Isolate } \\
\text { no. }\end{array}$ & Identity & Source* & M-type $\dagger$ & R-type & & $\begin{array}{c}\mathrm{M}-\mathrm{R} \\
\text { group }\end{array}$ & $\begin{array}{l}\text { PMS } \\
\text { group }\end{array}$ \\
\hline Al & C. albicans $\}$ & Blood culture & $\mathrm{N}-\mathrm{C}$ & AbCDEFG & $\mathrm{K}$ & AMl & API \\
\hline $\mathrm{A} 2$ & C. albicanss & Blood culture & $\mathrm{N}-\mathrm{C}$ & AbCDEFG & $\mathrm{K}$ & AMl & API \\
\hline A3 & C. albicans & Blood culture & D & a $B C E G$ & & AM2 & AP2 \\
\hline A4 & C. albicans $\}$ & Blood culture & D & a $B C E G$ & & AM2 & AP2 \\
\hline A5 & C. albicans. J & Urine & $\mathrm{D}$ & ABCDEFG & $\mathrm{ijk}$ & AMl & APl \\
\hline A6 & C. tropicalis & Blood culture & N-F & $\mathrm{AB} D$ & K & AM3 & AP3 \\
\hline A7 & C. ylabrata & Fareces & $\mathrm{O}$ & a B D F H & $\mathrm{Kl}$ & $\mathrm{AM} 4$ & AP4 \\
\hline A8 & C. albicans & Sputum & $\mathrm{N}-\mathrm{C}$ & A $C d E F G$ & $k$ & AMl & AP1 \\
\hline A9 & C. albicans & Sputum & $\mathrm{N}-\mathrm{C}$ & AbCDEFG & $\mathrm{K}$ & $\mathrm{AMI}$ & API \\
\hline
\end{tabular}

* Isolates from the same patient are bracketed.

$\uparrow$ See Materials and methods for codes.

\section{Interpretation of $M-R$ typing results}

Isolates were considered to be distinguishable when there was a difference of two major characters ${ }^{\curlyvee}(\mathrm{P}$. Hunter, personal communication). A single major difference was scored as a difference in fringe type, and good growth compared with no growth in resistotyping.

\section{$P M S$}

Cultures were blind-coded such that only their hospital source was known. The patient number was also given for isolates from hospital B. Isolates were grown on freshly prepared diagnostic sensitivity test (DST) agar plates incubated aerobically overnight at $37^{\circ} \mathrm{C}$, then subcultured in duplicate on DST. Each 


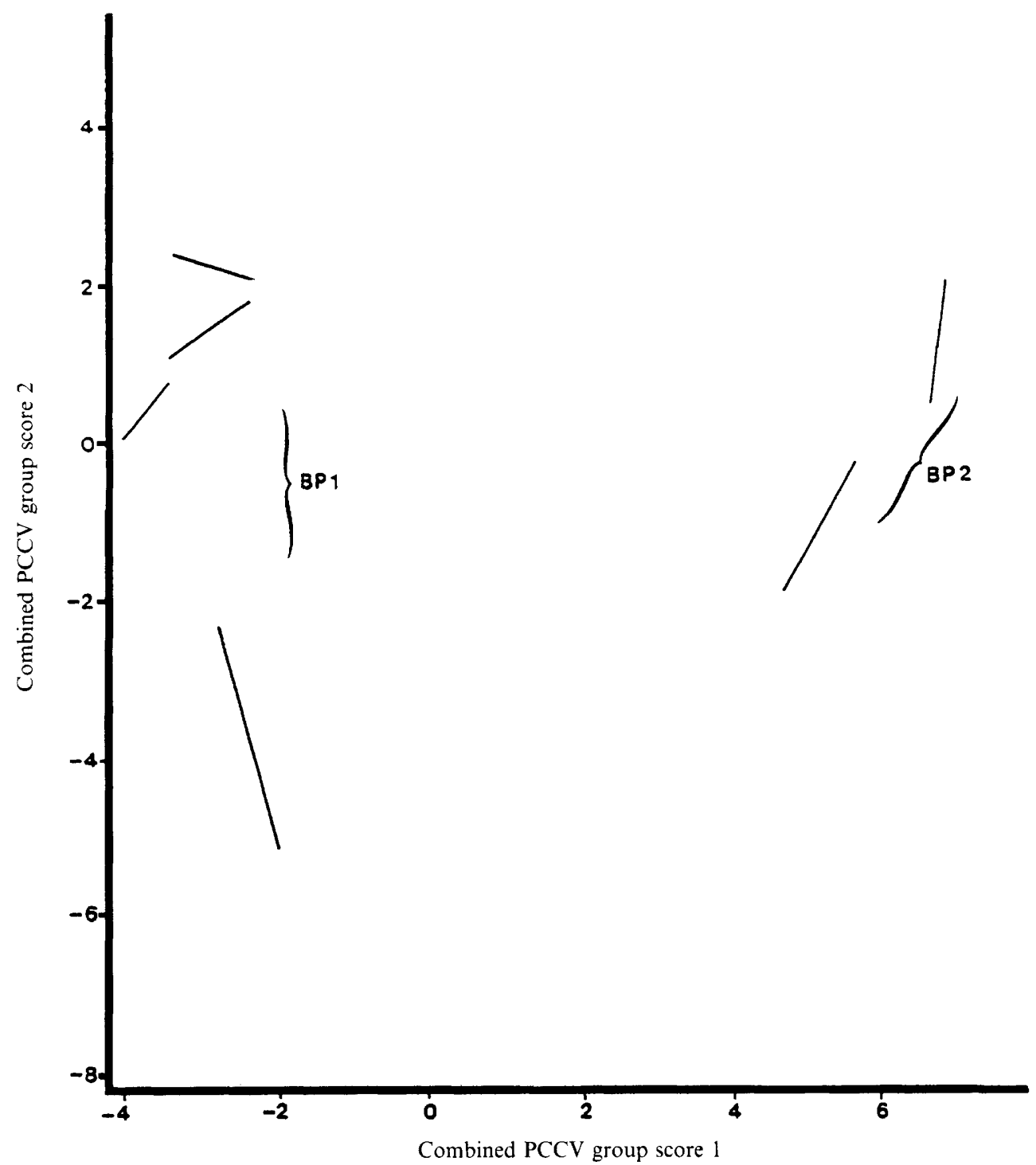

Fig. 2. Ordination diagram of spectral data on duplicate subcultures of six isolates of $C$. albicans from patient I. hospital B.

subculture was allocated a separate PMS number and pyrolysed in triplicate, at $530^{\circ} \mathrm{C}$ on a Horizon Instruments PYMS 200X pyrolysis mass spectrometer (Horizon Instruments Ltd, Heathfield, Sussex). Spectra for masses 51-200 were recorded on floppy disk, together with pyrolysis sequence number and total ion count.

\section{PMS data analysis}

After iterative normalisation to correct for variations in sample size, triplicate spectra sets for each subculture were labelled as distinct groups. The 150 mass ions were subjected to principal component (PC) and then canonical variate $(\mathrm{CV})$ analyses, as described previously. ${ }^{10.11}$ Results of these analyses are represented as ordination diagrams of the first two principal component canonical variates (PCCV1 rersus PCCV2).

Isolates were considered distinct if the line joining the means of the duplicate subculture replicates did not overlap or closely abut those of other strains. Clear outliers were removed from the dataset, and the data for the remaining isolates were then re-analysed in repeated steps. This process was terminated when the means of the groups resulting from triplicate analyses of separate subcultures of the same isolate were at least as different as those of different isolates. Such isolates were considered indistinguishable by PMS.

PMS datasets for isolates from hospitals A. B and C were analysed separately. PMS datasets for isolates from individual patients were also analysed separately for hospital B.

\section{Results}

\section{Reproducibility of $M-R$ typing}

Resistotyping was performed on all isolates on three separate occasions with two different batches of chemicals. The same result was required for each separate chemical on two occasions, with the third result being no more than one-half difference divergent. All chemicals satisfied these criteria. with the exception of malachite green (D). None of the duplicate cultures of an isolate differed to the degree that they would be resolved into different groups. 
Table II. Details of 25 isolates of C. albicans from hospital B

\begin{tabular}{|c|c|c|c|c|c|c|c|c|}
\hline $\begin{array}{c}\text { Patient } \\
\text { no. }\end{array}$ & $\begin{array}{c}\text { Isolate } \\
\text { no. }\end{array}$ & Source & M-type & R-type & & & $\begin{array}{l}\text { M-R } \\
\text { group }\end{array}$ & $\begin{array}{l}\text { PMS } \\
\text { group }\end{array}$ \\
\hline \multirow[t]{6}{*}{ I } & B1 & Tracheal aspirate & W-F & a BCdE G & $\mathrm{j}$ & & BM1 & BPl \\
\hline & $\mathrm{B} 2$ & Mouth & $\mathrm{N}-\mathrm{C}$ & a BC E G & $\mathrm{j}$ & & BM 1 & BP1 \\
\hline & B3 & Mouth & W-F & a b CDEFG & I & $\mathrm{K}$ & BM2 & BP2 \\
\hline & B4 & Tracheal aspirate & $\mathrm{N}-\mathrm{C}$ & a BC E G & $\mathrm{j}$ & & BM 1 & BPl \\
\hline & B5 & Tracheal aspirate & $\mathrm{N}-\mathrm{C}$ & a BC E G & $\mathrm{j}$ & & BMI & BP1 \\
\hline & B6 & Throat & W-F & a BCDEFG & $I$ & $\mathrm{~K}$ & BM2 & $\mathrm{BP} 2$ \\
\hline \multirow[t]{8}{*}{ II } & B7 & Throat & $\mathrm{N}-\mathrm{F}$ & a BCDE F G & I & $\mathrm{Kl}$ & BM3 & BP3 \\
\hline & B8 & Tracheal aspirate & N-F & a BCDEFG & I & KI & BM3 & BP3 \\
\hline & B9 & Gastric aspirate & N-F & a B CDEFG & I & $\mathrm{Kl}$ & BM3 & BP3 \\
\hline & $\mathrm{B} 10$ & Wound & $\mathrm{N}-\mathrm{F}$ & a B CDEFG & I & $\mathrm{Kl}$ & BM3 & BP3 \\
\hline & B11 & Throat & N-F & a BCDEFG & I & $\mathrm{Kl}$ & BM3 & BP3 \\
\hline & $\mathrm{B} 12$ & Gastric aspirate & $\mathrm{N}-\mathrm{F}$ & a BCDEFG & I & $\mathrm{Kl}$ & BM3 & BP3 \\
\hline & B13 & Wound & W-F & a BCDEFG & 1 & Kl & BM3 & BP3 \\
\hline & B14 & Wound drain & N-F & a BCDEFG & I & Kl & BM3 & BP3 \\
\hline \multirow[t]{6}{*}{ III } & B 15 & Gastric aspirate & $N-F$ & $G$ & & & BM4 & BP4 \\
\hline & B 16 & Throat & $\mathrm{D}$ & A CDEFG & & $\mathrm{K}$ & BM 5 & BP5 \\
\hline & $\mathrm{B} 17$ & Perineum & W-F & A C EFG & $\mathrm{i}$ & $\mathrm{K}$ & BM5 & BP6 \\
\hline & B18 & Gastric aspirate & $\mathrm{D}$ & A CdEFG & & $\mathrm{K}$ & BM5 & BP6 \\
\hline & B19 & Urine & W-F & A C EFG & $\mathrm{i}$ & $\mathrm{K}$ & BM5 & BP6 \\
\hline & B20 & Rectum & $\mathrm{N}-\mathrm{F}$ & A $C d$ e FG & & K & BM 5 & BP6 \\
\hline \multirow[t]{5}{*}{ IV } & B21 & Throat & $\mathrm{N}-\mathrm{C}$ & A CDEFG & $\mathrm{i}$ & K & BM6 & BP7 \\
\hline & B22 & Gastric aspirate & N-C & A CDEFG & $\mathrm{i}$ & K & BM6 & BP7 \\
\hline & B23 & Mouth & $\mathrm{N}-\mathrm{C}$ & A CDEFG & $\mathrm{i}$ & K & BM6 & BP7 \\
\hline & B24 & Tracheal aspirate & $\mathrm{N}-\mathrm{C}$ & A CDEFG & $\mathrm{i}$ & $\mathrm{K}$ & BM6 & BP7 \\
\hline & B25 & Perineum & W-F & $\mathrm{AbCDe} F G$ & $\mathrm{i} \mathrm{j}$ & $\mathrm{k}$ & BM6 & BP8 \\
\hline
\end{tabular}

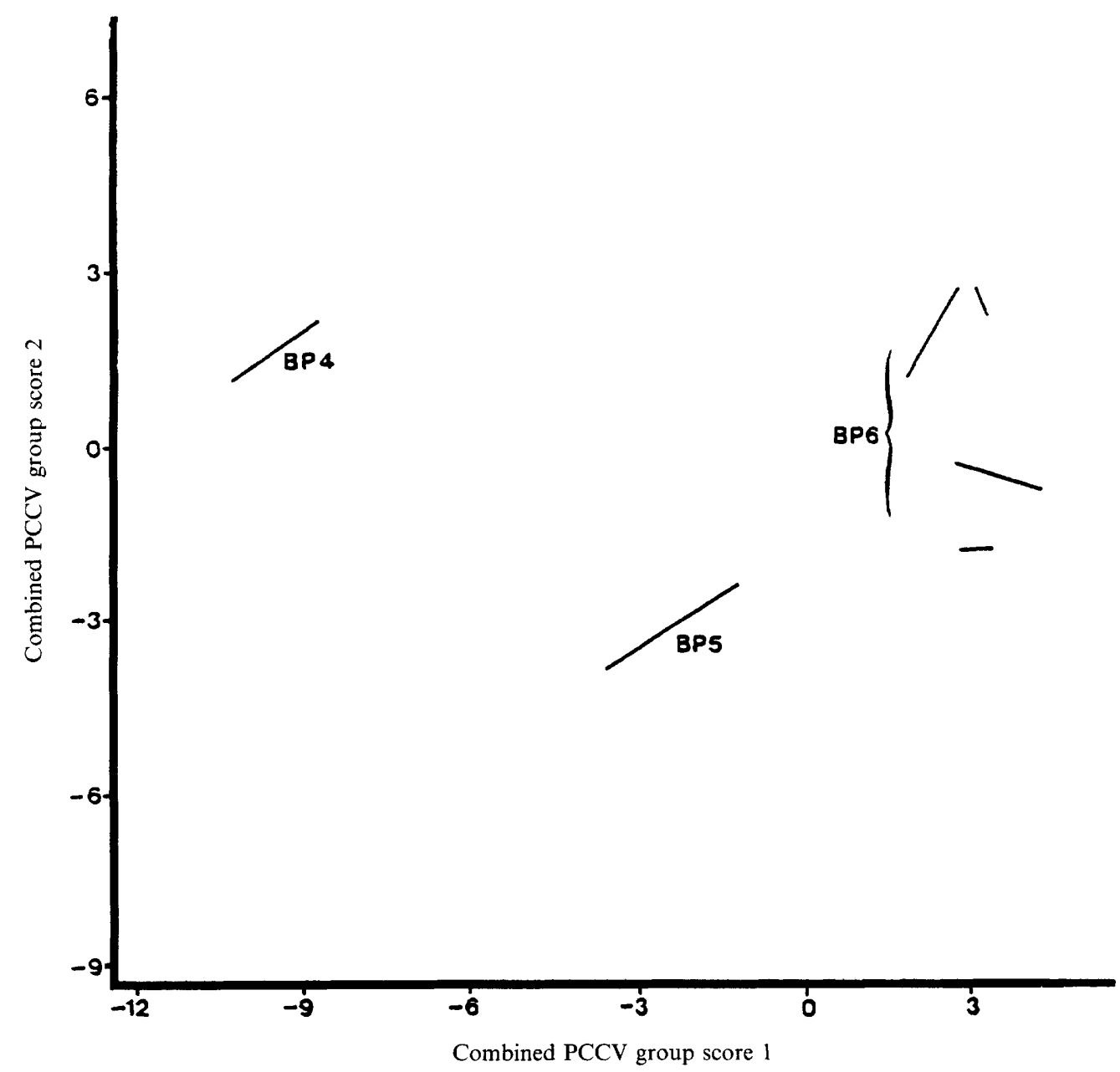

Fig. 3. Ordination diagram of spectral data on duplicate subcultures of six isolates of C. albicans from patient III, hospital B. 


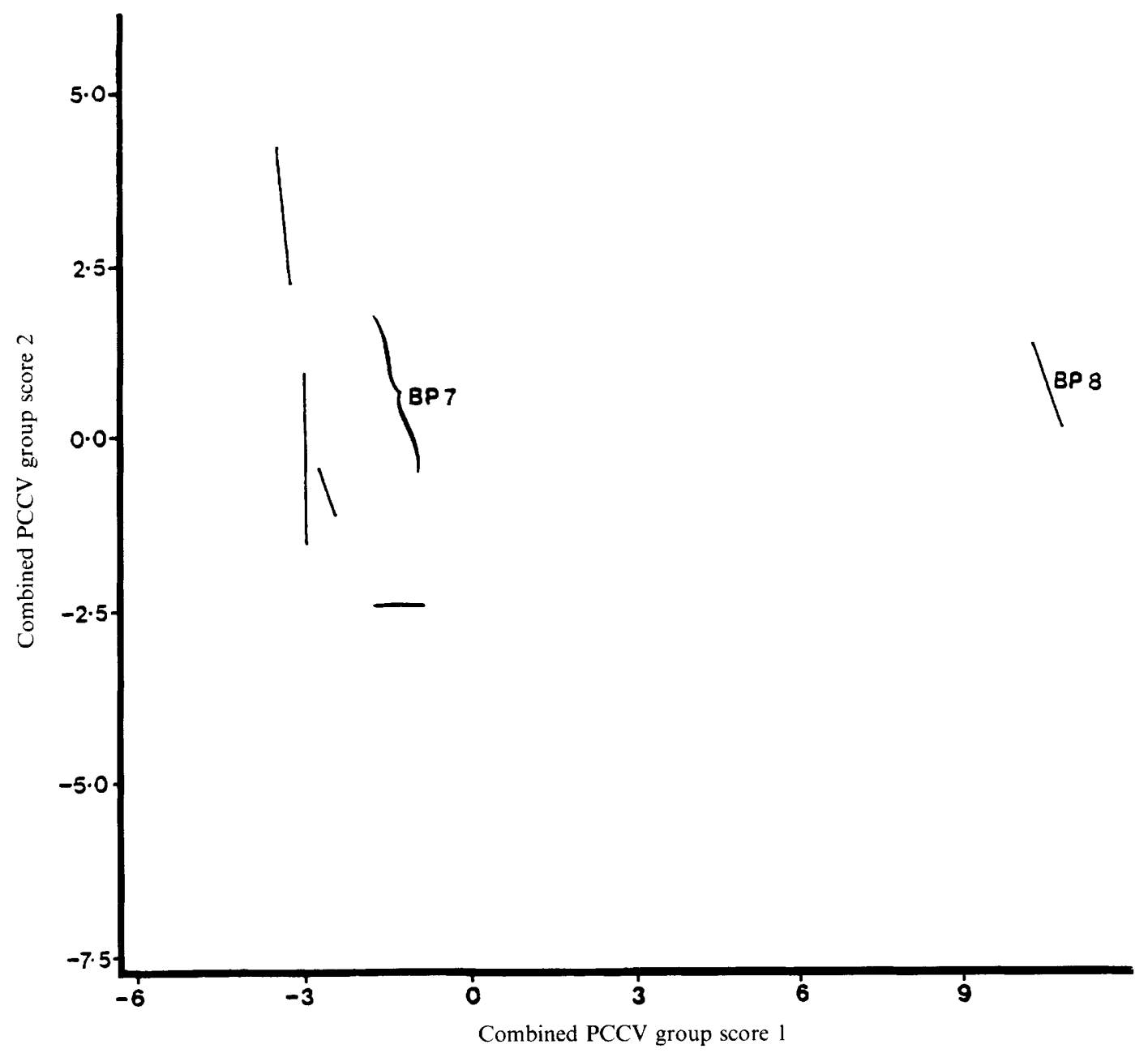

Fig. 4. Ordination diagram of spectral data on duplicate subcultures of five isolates of C. albicams from patient IV, hospital B.

\section{Hospital A}

PMS and M-R typing each resolved four groups of isolates from this hospital, and the isolate groupings were identical by the two methods (fig. 1, table I). Pyrolysis group API, and M-R typing group AM1, comprised isolates A1, A2, A5, A8 and A9. Pyrolysis group $\mathrm{AP} 2$, and $\mathrm{M}-\mathrm{R}$ typing group $\mathrm{AM} 2$ comprised isolates $\mathrm{A} 3$ and $\mathrm{A} 4$. Two single member groups comprised isolates A6 (AP3, AM3) and A7 (AP4, AM4); in view of the unusual resistotypes of these isolates, they were identified in the API 20C AUX system, and found to be C. tropicalis and C. glabrata, respectively.

\section{Hospital B: within-patient comparisons}

PMS and M-R typing each resolved two groups of isolates from patient $I$, with identical isolate groupings (fig. 2, table II). PMS group BP1, and M-R typing group BM1, comprised isolates B1, B2, B4 and B5. $\mathrm{BP} 2$ and $\mathrm{BM} 2$ comprised isolates $\mathrm{B} 3$ and $\mathrm{B} 6$ respectively.

All isolates from patient II were indistinguishable by PMS (BP3; data not shown) and were homogeneous by M-R typing (BM3; table II).
PMS resolved three distinct groups (BP4-BP6) of isolates from patient III (table II, fig. 3). BP4 comprised isolate $\mathrm{B} 15$; this strain was also distinct in M-R typing (BM4). BP5 comprised isolate B16, and BP6 comprised isolates $\mathrm{B} 17, \mathrm{~B} 18, \mathrm{~B} 19$ and $\mathrm{B} 20$. In $\mathrm{M}-\mathrm{R}$ typing the isolates of BP5 and BP6 formed a single group (BM5).

PMS resolved two distinct groups (BP7 and BP8) of isolates from patient IV (table II, fig. 4). BP7 comprised isolates $\mathrm{B} 21, \mathrm{~B} 22, \mathrm{~B} 23$ and $\mathrm{B} 24$, and $\mathrm{BP} 8$ comprised isolate $\mathrm{B} 25$. In $\mathrm{M}-\mathrm{R}$ typing the isolates of BP7 and BP8 formed a single group (BM6).

\section{Hospital B: PMS comparison of all isolates}

PMS comparison of all 25 isolates from hospital B (fig. 5) suggested that some strains were common to. but not necessarily predominant in, all of the patients. Isolates of PMS groups BP2 (patient I) were indistinguishable from isolates of BP3 (patient II). BP6 (patient III) and BP7 (patient IV). All were part of a cluster of 18 isolates distinguished from the remaining seven by PMS. With M-R typing, this cluster of 18 isolates could be separated into three distinct groups comprising isolates of (i) BM2 plus BM3; (ii) BM5 and (iii) BM6. 


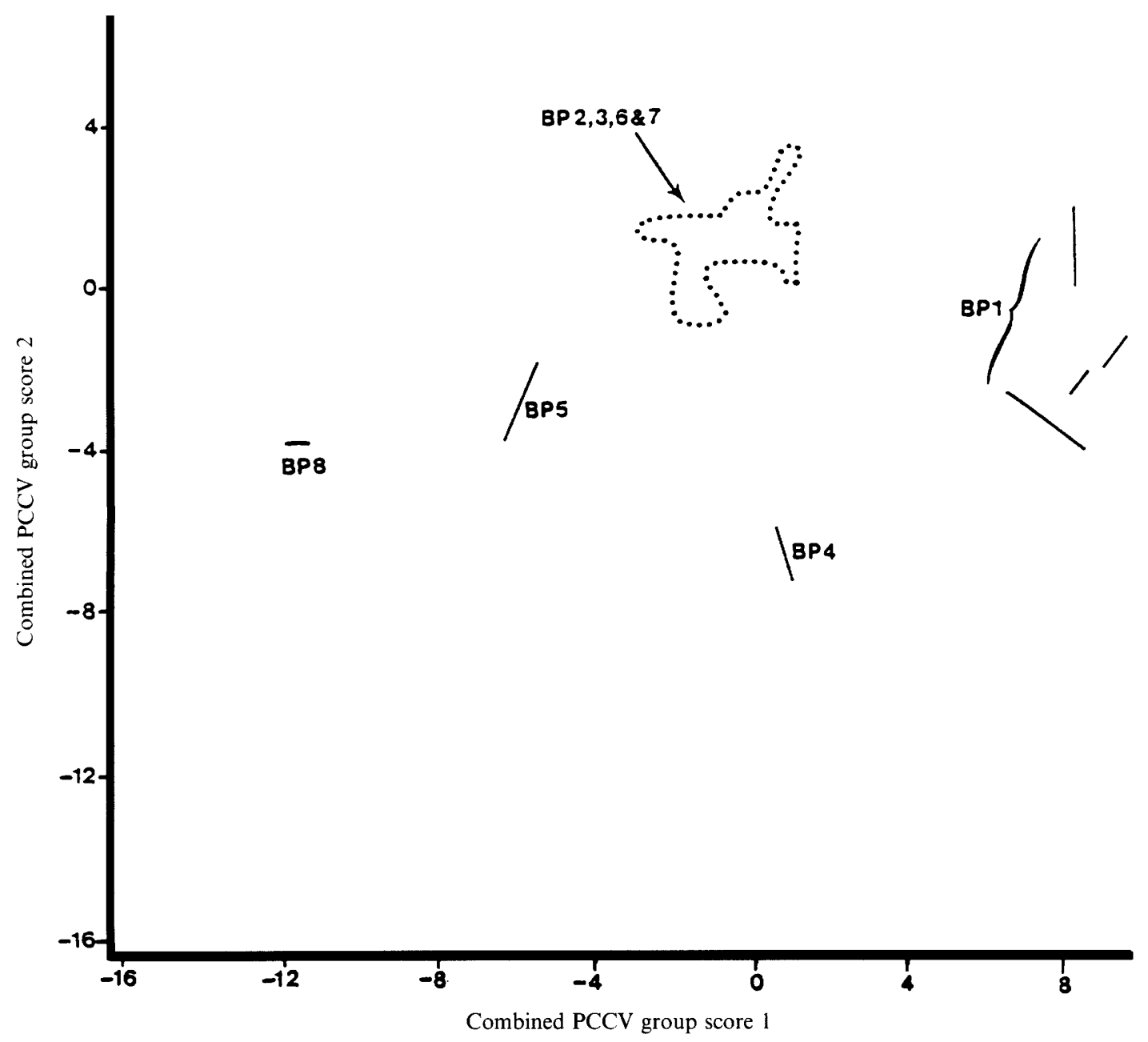

Fig. 5. Ordination diagram of spectral data on duplicate subcultures of 24 isolates of C. albicans from hospital B.

\section{Hospital C}

With PMS, three distinct groups (CP1, CP2 and CP3) of isolates were found (table III, fig. 6). CP1 comprised isolates $\mathrm{C} 1, \mathrm{C} 2, \mathrm{C} 3, \mathrm{C} 6$ and $\mathrm{C} 7 ; \mathrm{CP} 2$ comprised isolate $\mathrm{C} 4$; and $\mathrm{CP} 3$ comprised isolate $\mathrm{C} 5$. With M-R typing all seven of these isolates formed a single group (CM1).

\section{Discussion}

PMS and M-R characterisation yielded identical divisions of the isolates from hospital A. The two non$C$. albicans isolates from this outbreak were readily distinguished from the $C$. albicans isolates by PMS; similar large species differences were seen in the study of Magee et al. ${ }^{6}$ for C. krusei, C. tropicalis and $C$. albicans. PMS characterisation of isolates from hospital $C$ distinguished three groups of isolates, whereas $M-R$ typing failed to differentiate between these isolates.

PMS comparison of multiple isolates from individual patients from hospital B confirmed the M-R findings that all isolates from patient II were indistinguishable, as were the majority of isolates from patient IV, but patients I and III appeared to carry multiple strains. It is known that immunocom- promised patients may be colonised with a succession of different strains of $C$. albicans, ${ }^{12}$ and that healthy women may carry genetically distinct strains of $C$. albicans simultaneously in different anatomical locations. ${ }^{13}$ Therefore, it is essential, that epidemiological investigations of potential outbreaks include all isolates from each patient. More broadly, PMS indicated that all four patients involved in the potential outbreak at hospital B had yielded some closely similar isolates, suggesting nosocomial acquisition. However, for M-T typing, only patients I and II yielded indistinguishable isolates.

Overall, there was reasonable agreement between the M-R typing and PMS results. M-typing depends on detailed observation of colonial morphology, generating a bewildering array of codes that are difficult to compare within one laboratory and almost impossible to reproduce reliably in different centres." However, the modified coding system described ${ }^{*}$ simplifies analysis.

In resistotyping there are problems in defining clear, usable criteria for the distinction between growth and no growth. It is also difficult to standardise inocula ${ }^{2}$ and this can cause inter-assay variation. In this study a "definitive" set of resistotyping results was obtained by repeating the resistotyping at least three times and ensuring that the same pattern was obtained at least 


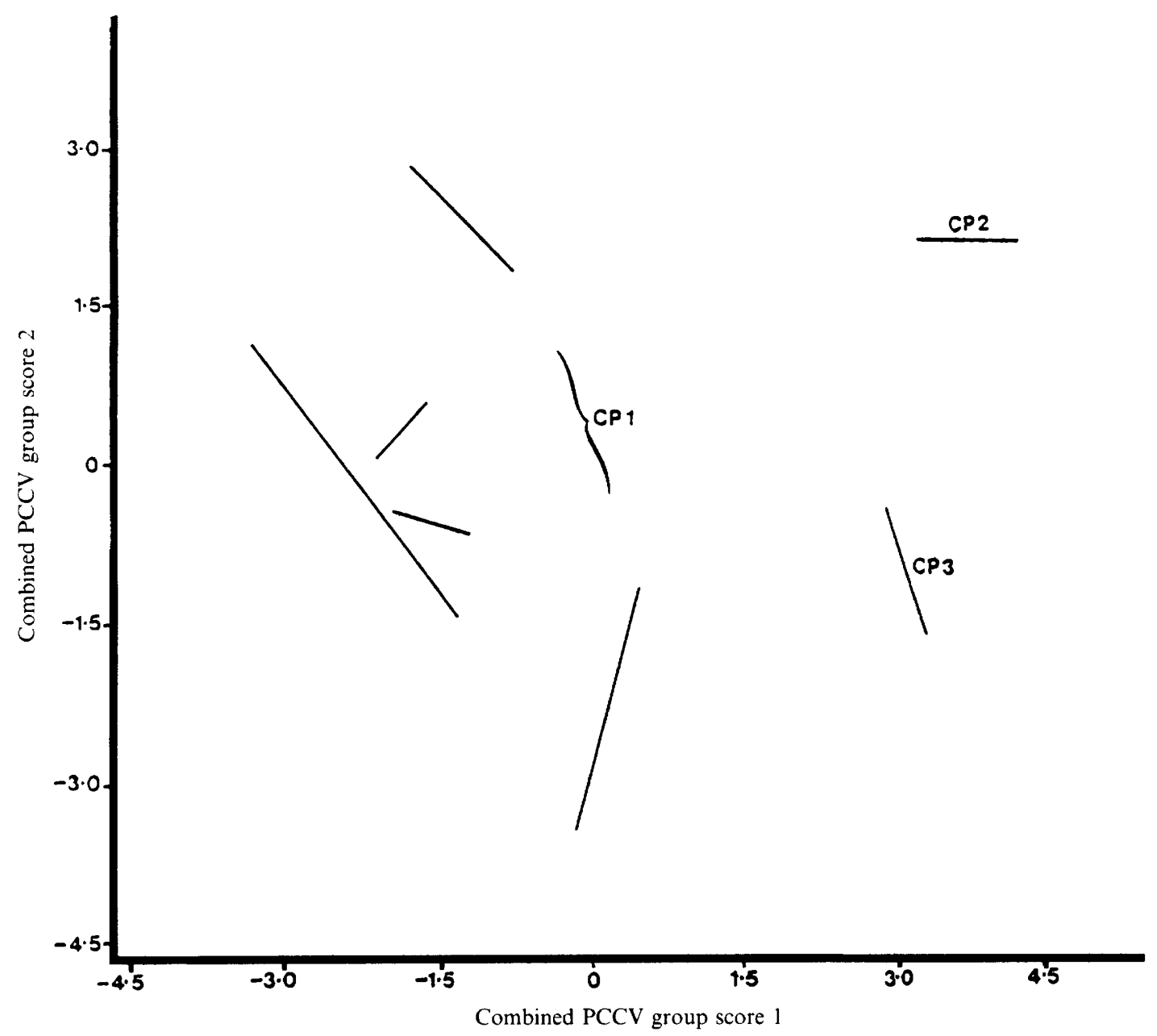

Fig. 6. Ordination diagram of spectral data on duplicate subcultures of seven isolates of $C$. albicans from hospital $C$.

Table III. Details of seven isolates of $C$. albicans from the neonatal intensive care unit in hospital $\mathrm{C}$

\begin{tabular}{|c|c|c|c|c|c|c|c|}
\hline $\begin{array}{c}\text { Isolate } \\
\text { no. }\end{array}$ & Source & M-type & R-type & & & $\begin{array}{l}\text { M-R } \\
\text { group }\end{array}$ & $\begin{array}{l}\text { PMS } \\
\text { group }\end{array}$ \\
\hline $\mathrm{Cl}$ & Baby & D & $\mathrm{AbCdeFG}$ & & K & $\mathrm{CM} 1$ & CPl \\
\hline $\mathrm{C} 2$ & Baby & $\mathrm{D}$ & $\mathrm{Abc} \quad \mathrm{EFG}$ & $\mathrm{i}$ & K & CM1 & $\mathrm{CP} 1$ \\
\hline C3 & Baby & D & $\mathrm{AbC}$ e FG & & $\mathrm{K}$ & CM1 & CP1 \\
\hline C4 & Baby & $\mathrm{D}$ & $\mathrm{AbC}$ EFG & $\mathrm{i}$ & K & CMl & $\mathrm{CP} 2$ \\
\hline C5 & Baby & W-F & $\mathrm{AbCDEFG}$ & $\mathrm{j}$ & $\mathrm{k}$ & CM1 & CP3 \\
\hline C6 & Incubator & $\mathrm{D}$ & $\mathrm{AbCdeFG}$ & & K & CM1 & CP1 \\
\hline $\mathrm{C} 7$ & Baby & $\mathrm{D}$ & $\mathrm{AbCdeFG}$ & & K & $\mathrm{CM} 1$ & CP1 \\
\hline
\end{tabular}

twice. Biotyping. ${ }^{14}$ serotyping ${ }^{15}$ and typing by sensitivity to killer toxins ${ }^{36}$ have been used to characterise Candida spp., but they are either insufficiently discriminatory between $C$. albicans strains or show poor intra- and inter-laboratory reproductibility. ${ }^{1.2}$

Typing by iso-enzyme pattern differences detected by electrophoretic separation on polyacrylamide gels has been described ${ }^{17}$ but the procedures are timeconsuming and require specialised equipment. Furthermore, inter-gel variations preclude comparisons of isolates run on separate gels, therefore this approach is unsuited to analysis of large isolate sets. ${ }^{2}$

Genotypic methods of strain delineation in $C$. albicans have concentrated on electrophoretic karyo- typing by use of contour-clamped homogeneous electric fields (CHEF) and restriction endonuclease analysis (REA) of genomic DNA. ${ }^{3.4}$ Vazquez et al. ${ }^{4}$ examined 35 separate clinical isolates of $C$. albicans and found 17 distinct types by REA and 23 types by CHEF. However, both techniques are expensive, labour-intensive and unlikely to become widely available to routine laboratories.

In contrast, PMS is a simple and rapid technique, capable of comparing up to 50 isolates. each in duplicate, in a single run, with a minimum of sample preparation.

Most other typing schemes may be perturbed by phenotypic switching in $C$. albicans, which appears to be caused by spontaneous variations during growth resulting in different colonial morphology. ${ }^{1}$ Switching is associated with concomitant alteration in cell physiology and biochemistry. Even karyotype differences have been reported to be associated with the colonial changes when switching occurs. ${ }^{18.19}$ Methods to induce switching all involve stressing the organism, such as growing at low temperature on nutrient-limited medium. Therefore, switching is perhaps less likely to be a problem in methods involving growth at $37^{\circ} \mathrm{C}$ on rich media, and there was certainly no obvious colonial variation observed in this study. However, as PMS allows samplings to avoid obvious colonial variants 
and no subsequent cell division is possible, PMS results should not be affected by the switching phenomenon.
PMS typing of $C$. albicans is quick, simple and capable of comparing large numbers of isolates.

\section{References}

1. Hunter PR. A critical review of typing methods for Candida alhicans and their applications. Crit Rer Microbiol 1991; 17: $417-434$

2. Merz WG. Candida albicans strain delineation. Clin Microbiol Rer 1990; 3: 321-334

3. Stevens DA. Odds FC, Scherer S. Application of DNA typing methods to Candida albicans epidemiology and correlations with phenotype. Rev Infect Dis 1990; 12: 258-266.

4. Vazquez JA. Beckley A. Sobel JD, Zervos M. Comparison of restriction enzyme analysis and pulsed-field gradient gel electrophoresis as typing systems for Candida albicans. $J$ Clin Microbiol 1991; 29: 962-967.

5. Pitt T. Burnt offerings or typing systems? J Hosp Infect 1991; 17: $157-158$.

6. Magee JT. Hindmarch JM, Duerden BI, MacKenzie DWR Pyrolysis mass spectrometry as a method for inter-strain discrimination of Candida albicans. J Gen Microbiol 1988; 134: $2841-2847$

7. Phongpaichit S, Mackenzie DWR, Fraser CM. Strain differentiation of Candida albicans by morphotyping. Epidemiol Infect 1987; 99: 421-428

8. Hunter PR. Fraser CAM. Application of a numerical index of discriminatory power to a comparison of four physiochemical typing methods for Candida albicans. $J$ Clin Microbiol 1989: 27: 2156-2160.

9. Medcraft JW. Typing of Candida and the epidemiology of candiosis. PhD thesis, University of Reading. 1985.

10. Aries RE. Gutteridge CS, Ottley TW. Evaluation of a low-cost, automated pyrolysis mass spectrometer. $J$ Anal Appl $P_{y}$ 1986; $91: 81-98$.

11. Orr K, Gould FK, Sisson P, Lightfoot NF, Freeman R, Burdess D. Rapid inter-strain comparison by pyrolysis mass spectrometry in nosocomial infection with Xanthomonas maltophilia. J Hosp Infect 1991; 17: 187-195.

12. Bruatto M. Vidotto V, Marinuzzi G, Raiteri R, Sinicco A Candida albicans biotypes in human immunodeficiency virus type 1 -infected patients with oral candidiasis before and after antifungal therapy. $J$ Clin Microbiol 1991; 29: 726- 730.

13. Soll DR. Galask R. Schmid J, Hanna C. Mac K. Morrow BC. Genetic dissimilarity of commensal strains of Candida spp. carried in different anatomical locations of the same healthy women. J Clin Microbiol 1991; 29: 1702-1710

14. Odds FC. Abbott AB. Modification and extension of tests for differentiation of Candida species and strains. Sahouraudia $1983 ; 21: 79-81$.

15. Brawner DL. Comparison between methods for serotyping of Candida albicans produces discrepancies in results. $J$ Clin Microbiol 1991; 29: 1020-1025

16. Lehmann PF, Cowan LE, Jones RM, Ferencak WJ. Use of killer fungi and antifungal chemicals in characterization of yeast species and biotypes. Trans $\mathrm{Br} M \mathrm{rcol}$ Soc 1987; 88: 199-206.

17. Lehmann PF, Kemker BJ, Hsiao C-B. Dev S. Isoenzyme biotypes of Candida species. J Clin Microbiol 1989;27: $2514-2521$

18. Dutton S, Penn CW. Biological attributes of colony-type variants of Candida albicans. J Gen Microhiol 1990: 135: 3363-3372.

19. Rustchenko-Bulac EP, Sherman F. Hicks JB. Chromosomal rearrangements associated with morphological mutants provide a means for genetic variation of Candida alhicans. J Bacteriol 1990; 172: 1276-1283. 